\title{
The Effects of Birth Weight on Newborn Apgar Score with Other Potential Medical and Child Risk Factors, Brussels Cohort Study
}

\author{
Article by Jerry-Jonas mbasha \\ Ph.D, Public Health, Texila American University, Congo \\ E-mail: jerrymbasha@gmail.com
}

\section{Introduction}

The new born weight is one of the major indicator providing information of the nine months' intrauterine life and may predict the survival rate of new born. In fact, birthweight is one of the most accessible and most misunderstood variables in epidemiology. A baby's weight at birth is strongly associated with mortality risk during the first year and, to a lesser degree, with developmental problems in childhood and the risk of various diseases in adulthood(1). Epidemiological analyses often regard birthweight as on the causal pathway to these health outcomes. Under this assumption of causality, birthweight is used to explain variations in infant mortality and later morbidity, and is also used as an intermediate health endpoint in itself.(1).

The scope of this study will not be extended to the measurement of news born health outcomes after one minutes of life. A second factor is that birthweight is an extremely powerful predictor of an individual baby's survival. In general, the lower the weight, the higher a baby's risk of infant mortality. On a population level, mean birthweight is associated with infant mortality. Groups with lower mean birth weight often have higher infant mortality $(1,2)$ (e.g. the infants of mothers who smoke, or of mothers with lower socioeconomic status). Finally, birthweight is associated with health outcomes later in life. Asthma, low IQ, and hypertension have all been reported to be more common among those who were small at birth(1). However, the birthweight standards that are used to determine gestational age are often applied without consideration of their appropriateness to the population under study(3). Thus, birth weight can't be considered itself in isolation, it need to be linked to other factors, both intrinsic (e.g. fetal, sex, ethnicity, maternal parity, and plurality of pregnancy) and extrinsic (e.g. mother's socio-economic characteristics maternal).(3). Standards that are most applicable to the infants under study will use available WHO proposed birth weight classification standards.(4).

It is also well known that baby weight may influence the mode of delivery (which in turn may significantly influence the APGAR score. Virginia Apgar, a physician and anesthesiologist, developed the Apgar scoring system in 1952 (Apgar, 1953) to evaluate a newborn's condition at birth. The Apgar score is performed at 1 and 5 minutes of life. However other studies proposed to score it up to 10 minutes of life of newborn. Under this study we shall consider only APGAR score at 1 minute which will relatively help us to conclude on the well-being of newborn without any intention to provide more information of future newborn health outcomes under this study. By future outcomes we refer to all new born development, survival or death. Though some studies suggest the existence of association between low APGAR score and newborn development (neurological, physical, school performance, etc.). Predicting low Apgar scores may allow the appropriate planning of neonatal care. Previous work showed that socioeconomic as well as biological factors of the mother can be predictors of Apgar scores. For example, low social class, poor educational level and adverse social circumstances have been associated with lower Apgar scores in previous studies(5-9). Of course, adverse events during pregnancy and birth such as maternal infection, mode of delivery may also influence Apgar score but up to which extent?

However, some assumptions may be raised upon Apgar result which is one of the outcomes. Some child factors have been also mentioned but not fully documented in the outcome of Apgar at 1 and 5 minutes. Such as gestational age, gender, girls having good delivery outcome in terms of Apgar compare to newborn boys of the same gestational age. 
DOI: $10.21522 / \mathrm{TIJPH} .2013 .05 .04$. Art017

ISSN: $2520-3134$

\section{Study objectives}

The objective of this cohort study was to explore the associations between parents' characteristics and birth weight, Apgar score considering Apgar score at one minute along with 2 potential modifiers: Medical intervention and Child related characteristics at time of delivery.

\section{Methods}

\section{Study population and setting}

This study is a population-based cohort study done in Brussels using the Belgian civil registration system which provide information on babies born during the year 1998-2009 in Belgium knowing that all live births and fetal deaths from 22 completed weeks of gestation are recorded in Belgium registration system. The Brussels Health Observatory is responsible for the management and analysis of data from birth and death certificates for the Brussels population.

\section{Study design and sample}

Data used in the present study relate a sample size of babies born during 1998-2009; One thousand nine hundred and nine women who delivered a pregnancy of 22 weeks of gestational age were included in the study. Note that in Belgium data are exchanged with Flanders, and as such, we receive data from birth and death certificates for infants of mothers living in Brussels who deliver in Flanders. Corresponding data for Wallonia are available but have a more than five-year delay and could therefore not be included. The majority of births occurring outside of Belgium to Brussels residents were not included. Birth certificates consulted detailed obstetrical information collected at birth by midwives and medical doctors.

Inclusion Criteria: Mothers living in Brussels irrespective of the place of delivery and country of origin. Exclusion Criteria: Data for Wallonia were more than five-year delay and could therefore not be included. Births occurring outside of Belgium to Brussels residents were not included.

\section{Choices of variables}

Considering the study objectives, to explore the effect of birth weight on Apgar score considering Apgar score at one minute along with other potential modifiers: Medical intervention and Child characteristics at time of delivery, also parent's characteristics will be assessed to find the association with birth weight and Apgar score at one minute. thirteen independent variables were chosen for analysis summarized in three types: parent's socio-demographic variables, child status at birth, medical intervention related variables all of them are dichotomized or categorized and two major outcomes, the Birth weight and Apgar score at one minute.

The Parents Socio-demographic variables include:

1. The maternal education Level will be categorized in primary school, secondary (inferior and superior), the superior and missing (unknown and others were grouped together).

2. The Maternal activity ${ }^{1}$ : has been documented as associated to low birth weight as mentioned above. And has been categorized into two categories (with occupation and without occupation).

3. Maternal civil status: is categorized in single, married widow, divorced, separated and unknown

4. Medical risk factor: include factors which may impact the newborn weight or Apgar such as malnutrition, chronic diseases such as HIV, diabetes, etc.

5. Mother age $^{2}$ : has been considered in three categories: Young mother, middle age mother and advanced age mothers.

6. Multiple birth ${ }^{3}$ has been coded as Yes and No. considering that yes means more than one child bearing.

${ }^{1}$ Variable which may influence Apgar (see the figure above)

${ }^{2}$ Variables which may influence Apgar (see the figure above) 
7. Maternal nationality of origin ${ }^{4}$ : it has 9 categories and unknown category has been converted to missing as representing $27 \%$ of the whole data which is significant and studies has proven its significantly associated with new born outcome such as birth weight.

8. Paternal nationality of origin: as for the maternal nationality of origin, the variable has 9 categories and unknown category variables have been converted to missing and representing $31 \%$ of the whole data for this category.

-Variables related to child status:

9. Child gender: dichotomous variables, boys and girls. It has been empirically documented that boys are weak at birth compare to girls of the same gestational age with boys having high risk of low Apgar while going through the same delivery procedure.

10. Gestational age: the variable has been categorized into 2 group: the baby`s delivery Term (in weeks), it was categorized into premature babies labelled as "22-36" and term babies labelled as "37-42".

11. Child Presentation: it has 5 categories which include the head down, transverse, seat, other head presentation and missing/others. Considering the mode of delivery able to

\section{Medical intervention variables:}

12. The delivery: this variable may largely influence the Apgar score. The medical intervention by instrumental vaginal birth (forceps or vacuum), cesarean section or normal delivery will may influence the Apgar score.

13. The Assistance: during the delivery may also influence the Apgar score. This refer to skills of medical staff, midwives on providing assistance to women in labor and the new born. Medical assistance may benefit or not to the new born in improving or not the Apgar score.

\section{The outcomes}

These are variables which tell us about the child`s health status after delivery.

1. The APGAR at $1^{\text {st }}$ minute and the APGAR at $5^{\text {th }}$ minute are all dichotomously categorized to "less than 7" and "Equal to or greater than 7". Less than 7 was considered as depressed and less above 7 as normal.

2.The baby`s Birth weight was categorized into categories those with low birth weight labelled "Less than $2.5 \mathrm{~kg}$ " which is the event under this outcome and those with normal birth weight labelled "Equal to or greater than $2.5 \mathrm{~kg}$ ".

\footnotetext{
${ }^{3}$ Variable which may influence Apgar (see the figure above)

${ }^{4}$ Variable which may influence Apgar (see the figure above)
} 
DOI: $10.21522 / \mathrm{TIJPH} .2013 .05 .04 . A r t 017$

ISSN: $2520-3134$

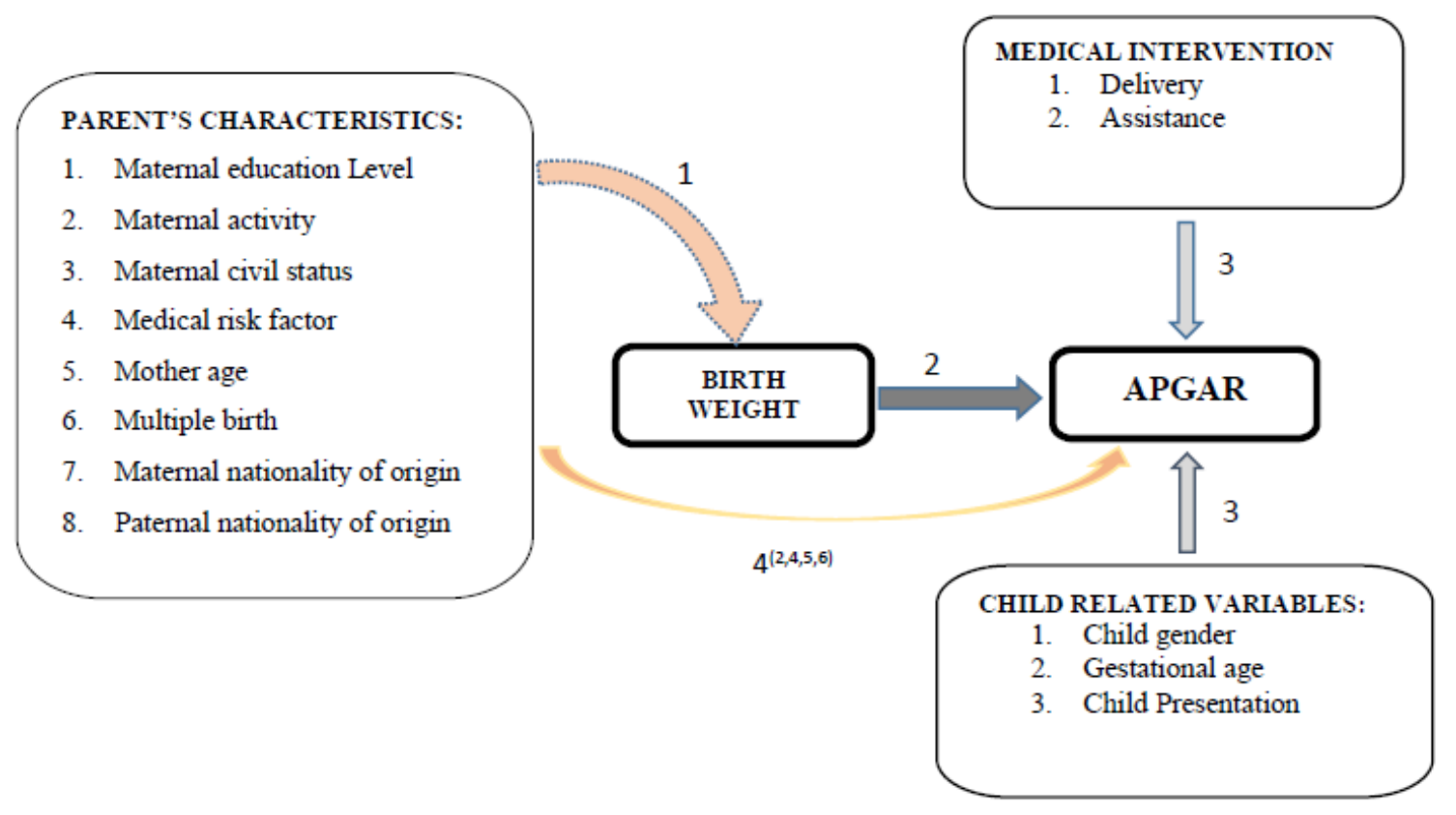

\section{Statistical analyses}

Statistics description of variables providing number of subjects, related frequencies in number and proportion.

The univariate analyses were used to compare the frequencies of the socio-demographic and potential risk factors variables between independent variables to the outcome. With all these variables being categorical, we tested for associations between the variables and the outcome using Pearson Chi-squared test and alternately.

For variables with more than two categories, the latter adjustments were done using logistic regression in order to obtain possible confounders.

The multivariate analysis was done using an exploratory approach to build the model with a stepwise selection procedure for all dependent variables and outcomes (Birth weight and Apgar) variables based on the log likelihood. We then performed a stratified analysis using the independent variables that were either socio-demographic and remained significant after the exploratory approach, a potential risk factors significant in univariate analyses or iii) those that are confirmed in literature as risk factors. Missing values with less than $10 \%$ of proportion was included in others or unknown category for the analysis. However, missing values of more than $10 \%$ from a variable was considered as missing and a specific category named missing was created.

The goodness of fit of the model was verified using the Hosmer and Lemeshow`s test (non-significant results considered the model as good fit for the data). Potential multicollinearity concern between predictors and outliers were verified using the Variance Inflator Factor (VIF) and Standardized Pearson residuals respectively. Adjusted odds ratios for Birth outcome and Apgar and their corresponding 95\% C.I were then obtained from this final regression model. We finally compare the birth weight effect on Apgar at one minute and adjusted by strong risk. The likelihood ratio used to select the variables included in the final model was set at $p$-value 0.05 . STATA 13.1 software was used for statistical analysis. 


\section{Results}

\section{Baseline characteristics}

The Table 1 provide characteristics description for each variable in the study and description of categories created for each variable. Some categorical variables as missing appeared in two variables (in maternal education level and maternal/paternal nationality of origin).

1909 babies born in Belgium were taken into consideration for the analysis but lack of information such for missing values has reduced the sample size in each variable. This is noticed for delivery, assistance and gestational age.

\begin{tabular}{|c|c|c|c|}
\hline $\begin{array}{l}\text { Characteristics of Selected } \\
\text { Variables }\end{array}$ & $\mathbf{n}$ & Frequency & $(\%)$ \\
\hline Maternal education Level & 1909 & & \\
\hline Primary & & 185 & 9.7 \\
\hline Secondary inferior & & 231 & 12.1 \\
\hline Secondary superior & & 707 & 37 \\
\hline Superior & & 592 & 31 \\
\hline missing & & 194 & 10.2 \\
\hline Maternal activity & 1908 & & \\
\hline with occupation & & 857 & 44.9 \\
\hline without occupation & & 1051 & 55.1 \\
\hline Maternal civil status & 1908 & & \\
\hline No married & & 568 & 29.8 \\
\hline married & & 1340 & 70.2 \\
\hline Medical risk factor & 1909 & & \\
\hline Yes & & 249 & 13 \\
\hline No & & 1431 & 75 \\
\hline Missing & & 229 & 12 \\
\hline Mother age & 1909 & & \\
\hline Young mother & & 50 & 2.6 \\
\hline Middle age mother & & 1463 & 76.7 \\
\hline Advanced age mother & & 396 & 20.7 \\
\hline Multiple birth & 1909 & & \\
\hline Yes & & 74 & 3.9 \\
\hline No & & 1835 & 96.1 \\
\hline Maternal nationality of origin & 1909 & & \\
\hline Belgium & & 429 & 22.5 \\
\hline EU27 & & 208 & 10.9 \\
\hline East Europe+ Russia & & 53 & 2.8 \\
\hline Turkey & & 39 & 2 \\
\hline Maghreb & & 75 & 3.9 \\
\hline Sub-Sahara Africa & & 353 & 18.5 \\
\hline Others & & 117 & 6.1 \\
\hline Europe others & & 116 & 6.1 \\
\hline missing & & 519 & 27.2 \\
\hline Paternal nationality of origin & 1909 & & \\
\hline Belgium & & 411 & 21.5 \\
\hline EU27 & & 202 & 10.5 \\
\hline
\end{tabular}


DOI: $10.21522 /$ TIJPH.2013.05.04.Art017

ISSN: $2520-3134$

\begin{tabular}{|c|c|c|c|}
\hline East Europe+ Russia & & 32 & 1.7 \\
\hline Turkey & & 34 & 1.8 \\
\hline Maghreb & & 81 & 4.2 \\
\hline Sub-Sahara Africa & & 358 & 18.7 \\
\hline Others & & 92 & 4.9 \\
\hline Europe others & & 110 & 5.8 \\
\hline missing & & 589 & 30.9 \\
\hline Delivery & 1818 & & \\
\hline Normal & & 1333 & 73.3 \\
\hline Instrumental vaginal Birth & & 158 & 8.7 \\
\hline Caesarean & & 327 & 18 \\
\hline Assistance & 1812 & & \\
\hline Yes & & 502 & 27.7 \\
\hline No & & 1310 & 72.3 \\
\hline Child gender & 1909 & & \\
\hline Boy & & 1012 & 53 \\
\hline Girl & & 897 & 47 \\
\hline Gestational age & 1807 & & \\
\hline Normal & & 1560 & 86.3 \\
\hline Preterm & & 247 & 13.7 \\
\hline Child Presentation & 1909 & & \\
\hline Head down & & 1507 & 78.9 \\
\hline Other head presentation & & 32 & 1.7 \\
\hline seat & & 74 & 3.9 \\
\hline Transverses & & 12 & 0.6 \\
\hline Missing/other & & 284 & 14.9 \\
\hline
\end{tabular}

The statistical description of outcomes in (table 2), the birth weight was considered with a cutoff point of 2500 grams. New born of weight $<2500$ grams were considered as having low birth weight and new born with weight $\geq 2500$ grams were considered as Normal birth weight. The total sample size for birth weight is 1856 with 53 missing values as lack of information. (normal birth weight $n=1,712(92.24 \%)$ and low birth weight $\mathrm{n}=144(7.76 \%))$.

Ten independent variables were selected for the analysis with Birth weight which include the maternal education level, maternal activity, maternal civil status, medical risk factor, mother age, multiple birth, mother nationality of origin, paternal nationality of origin, child gender and gestational age. They are dichotomous or having more than 2 category (table2)

The Apgar score was considered at 1 minute of life. The lack of enough subjects could not enable the analysis to be extended to 5 minutes which is more appropriate for Apgar score analysis with comparison of new born of Apgar at 1 minute and Apgar at 10 minutes. Total sample size for Apgar at one minute is 1830 with 79 missing values as lack of information (normal Apgar $n=1,677$ (91.64\%) and Depressed $\mathrm{n}=153(8.36 \%)$ ). Nine variables were considered for the analysis which include Maternal activity, Medical risk factor, Mother age, Multiple birth, Delivery, assistance, child gender, Gestational age and Child presentation. 
Independent variables are dichotomous or having more than 2 categories. All two outcomes are dichotomous. The reference variables were chosen based on the literature and studies evidence.

Table 2. Descriptive statistics of outcomes (Birth weight and Apgar)

\begin{tabular}{llll}
\hline Outcomes variables & $\mathbf{n}$ & Frequency & $(\%)$ \\
\hline 1.Birth weight & 1856 & & \\
Normal birth weight & & 1712 & 92.2 \\
Low birth weight & & 144 & 7.8 \\
\hline 2.Apgar score at one minute & 1830 & & \\
Normal & & 1677 & 91.6 \\
Depressed & & 153 & 8.4 \\
\hline
\end{tabular}

The univariate analysis (table 3) of the BW considering that the event is Low birth weight (LBW). Main risk factors associated to the outcome statistically significant include the Preterm Birth which is strongly associated with LBW when a women deliver a preterm baby the risk of LBW is very high with the OR $(95 \%$ C.I $)=27.14$ 17.75-41.51, $p$-value $<0.001$; The Multiple Birth is also significantly associated with low birth weight for women who reported more than one delivery OR (95\% C.I) $=20.19$ (12.1833.46); Medical risk factors are also associated with low birth weight at OR (95\% C.I) $=6,39(4,29-9,52)$.

\begin{tabular}{|c|c|c|c|}
\hline Parents characteristics & $\begin{array}{l}\text { Low Birth } \\
\text { weight } \\
\text { n=144 }\end{array}$ & $\begin{array}{l}\text { Normal } \\
\text { Birthweight } \\
n=1712\end{array}$ & OR (IC 95\%) \\
\hline \multicolumn{4}{|l|}{ Maternal education } \\
\hline \multicolumn{4}{|l|}{ Level } \\
\hline Primary & 7.3 & 92.7 & $1(0.5-1.9)$ \\
\hline Secondary inferior & 9.25 & 90.75 & $1.3(0.76-2.2)$ \\
\hline Secondary superior & 7.25 & 92.75 & 1 \\
\hline Superior & 8.23 & 91.77 & $1.1(0.75-1.73)$ \\
\hline missing & 6.84 & 93.16 & $0.94(0.49-1.76)$ \\
\hline \multicolumn{4}{|l|}{ Maternal activity } \\
\hline with occupation & 7.38 & 92.62 & 1 \\
\hline without occupation & 8.07 & 91.93 & $1.1(0.78-1.55)$ \\
\hline \multicolumn{4}{|l|}{ Maternal civil status } \\
\hline No married & 8.83 & 91.17 & $1.22(0.86-1.76)$ \\
\hline married & 7.31 & 92.69 & 1 \\
\hline \multicolumn{4}{|l|}{ Medical risk factor } \\
\hline Yes & 22.22 & 77.78 & $6,39(4,29-9,52)$ \\
\hline No & 4.28 & 95.72 & 1 \\
\hline Missing & 14.29 & 85.71 & $3,73(2,34-5,93)$ \\
\hline \multicolumn{4}{|l|}{ Mother age } \\
\hline Young mother & 8 & 92 & $1.1(0.38-3.1)$ \\
\hline Middle age mother & 7.31 & 92.69 & 1 \\
\hline Advanced age mother & 9.4 & 90.6 & $1.31(0.88-1.95)$ \\
\hline \multicolumn{4}{|l|}{ Multiple birth } \\
\hline Yes & 5.83 & 94.17 & $\begin{array}{l}20.19(12.18- \\
33.46)\end{array}$ \\
\hline No & 55.56 & 44.44 & 1 \\
\hline
\end{tabular}

Maternal nationality of 
DOI: $10.21522 / \mathrm{TIJPH} .2013 .05 .04 . A r t 017$

ISSN: $2520-3134$

\begin{tabular}{llll}
\hline origin & & & \\
Belgium & 8.96 & 91.04 & 1 \\
EU27 & 9.14 & 90.86 & $1.02(0.56-1.84)$ \\
East Europe+Russia & 3.85 & 96.15 & $0.40(0.095-1.7)$ \\
Turkey & 2.63 & 97.37 & $0.27(0.36-2.05)$ \\
Maghreb & 11.11 & 88.89 & $1.27(0.56-2.85)$ \\
Sub-Sahara Africa & 7.14 & 92.86 & $0.78(0.46-1.32)$ \\
Others & 5.22 & 94.78 & $0.55(0.23-1.36)$ \\
Europe others & 7.96 & 92.04 & $0.87(0.41-1.88)$ \\
missing & 7.51 & 92.49 & $0.82(0.51-1.32)$ \\
\hline Paternal nationality of & & & \\
origin & & & \\
Belgium & 8.81 & 91.19 & 1 \\
EU27 & 6.06 & 93.94 & $0.66(0.33-1.32)$ \\
East Europe+Russia & 3.12 & 96.88 & $0.33(0.044-2.52)$ \\
Turkey & 3.03 & 96.97 & $0.32(0.042-2.44)$ \\
Maghreb & 10.39 & 89.61 & $1.2(0.53-2.7)$ \\
Sub-Sahara Africa & 7.37 & 92.63 & $0.82(0.48-1.40)$ \\
Others & 5.56 & 94.44 & $0.60(0.23-1.60)$ \\
Europe others & 11.01 & 88.99 & $1.28(0.63-2.56)$ \\
missing & 7.79 & 92.21 & $0.87(0.54-1.39)$ \\
\hline Child gender & & & \\
Boy & 7.35 & 92.65 & $0.88(0.63-1.24)$ \\
Girl & 8.22 & 91.78 & 1 \\
\hline Gestational age & & & \\
Normal & 2.27 & 97.73 & 1 \\
\hline
\end{tabular}

Table 3. Effect of demographic, health and socio-economics status of parents on birth weight

\begin{tabular}{lllll}
\hline & $\begin{array}{l}\text { Low Birth } \\
\text { weight }\end{array}$ & $\begin{array}{l}\text { Normal } \\
\text { Birth } \\
\text { weight }\end{array}$ & OR (CI 95\%) & p-value \\
Parents Characteristics & n=144 & n=1712 & & \\
\hline $\begin{array}{l}\text { Maternal education } \\
\text { Level }\end{array}$ & & & & \\
$\begin{array}{l}\text { Primary } \\
\text { Secondary inferior }\end{array}$ & 7.3 & 92.7 & $1(0.5-1.9)$ & $0.84^{*}$ \\
Secondary superior & 7.25 & 90.75 & $1.3(0.76-2.2)$ & \\
Superior & 8.23 & 92.75 & 1 & \\
missing & 6.84 & 91.77 & $1.1(0.75-1.73)$ & \\
Maternal activity & & 93.16 & $0.94(0.49-1.76)$ & \\
with occupation & 7.38 & & & 0.57 \\
without occupation & 8.07 & 92.62 & 1 & \\
\hline Maternal civil status & & 91.93 & $1.1(0.78-1.55)$ & \\
No married & 8.83 & & & \\
married & 7.31 & 91.17 & $1.22(0.86-1.76)$ & 0.26 \\
\hline
\end{tabular}

Medical risk factor 
Texila International Journal of Public Health Volume 5, Issue 4, Sep 2017

\begin{tabular}{|c|c|c|c|c|}
\hline Yes & 22.22 & 77.78 & $6,39(4,29-9,52)$ & $<0.001$ \\
\hline No & 4.28 & 95.72 & 1 & \\
\hline Missing & 14.29 & 85.71 & $3,73(2,34-5,93)$ & \\
\hline \multicolumn{5}{|l|}{ Mother age } \\
\hline Young mother & 8 & 92 & $1.1(0.38-3.1)$ & $0.4125^{*}$ \\
\hline Middle age mother & 7.31 & 92.69 & 1 & \\
\hline Advanced age mother & 9.4 & 90.6 & $1.31(0.88-1.95)$ & \\
\hline \multicolumn{5}{|l|}{ Multiple birth } \\
\hline Yes & 5.83 & 94.17 & $\begin{array}{l}20.19(12.18- \\
33.46)\end{array}$ & $<0.001$ \\
\hline No & 55.56 & 44.44 & 1 & \\
\hline \multicolumn{5}{|c|}{$\begin{array}{l}\text { Maternal nationality of } \\
\text { origin }\end{array}$} \\
\hline Belgium & 8.96 & 91.04 & 1 & $0.5485^{*}$ \\
\hline EU27 & 9.14 & 90.86 & $1.02(0.56-1.84)$ & \\
\hline East Europe + Russia & 3.85 & 96.15 & $0.40(0.095-1.7)$ & \\
\hline Turkey & 2.63 & 97.37 & $0.27(0.36-2.05)$ & \\
\hline Maghreb & 11.11 & 88.89 & $1.27(0.56-2.85)$ & \\
\hline Sub-Sahara Africa & 7.14 & 92.86 & $0.78(0.46-1.32)$ & \\
\hline Others & 5.22 & 94.78 & $0.55(0.23-1.36)$ & \\
\hline Europe others & 7.96 & 92.04 & $0.87(0.41-1.88)$ & \\
\hline missing & 7.51 & 92.49 & $0.82(0.51-1.32)$ & \\
\hline \multicolumn{5}{|l|}{$\begin{array}{l}\text { Paternal nationality of } \\
\text { origin }\end{array}$} \\
\hline Belgium & 8.81 & 91.19 & 1 & $0.5545^{*}$ \\
\hline EU27 & 6.06 & 93.94 & $0.66(0.33-1.32)$ & \\
\hline East Europe + Russia & 3.12 & 96.88 & $0.33(0.044-2.52)$ & \\
\hline Turkey & 3.03 & 96.97 & $0.32(0.042-2.44)$ & \\
\hline Maghreb & 10.39 & 89.61 & $1.2(0.53-2.7)$ & \\
\hline Sub-Sahara Africa & 7.37 & 92.63 & $0.82(0.48-1.40)$ & \\
\hline Others & 5.56 & 94.44 & $0.60(0.23-1.60)$ & \\
\hline Europe others & 11.01 & 88.99 & $1.28(0.63-2.56)$ & \\
\hline missing & 7.79 & 92.21 & $0.87(0.54-1.39)$ & \\
\hline \multicolumn{5}{|l|}{ Child gender } \\
\hline Boy & 7.35 & 92.65 & $0.88(0.63-1.24)$ & 0.4835 \\
\hline Girl & 8.22 & 91.78 & 1 & \\
\hline \multicolumn{5}{|l|}{ Gestational age } \\
\hline Normal & 2.27 & 97.73 & $\begin{array}{l}1 \\
27.14(17.75-\end{array}$ & $<0.001$ \\
\hline Preterm & 38.66 & 61.34 & 41.51) & \\
\hline
\end{tabular}

*P-value for the global test 
DOI: $10.21522 / \mathrm{TIJPH} .2013 .05 .04 . A r t 017$

ISSN: $2520-3134$

Others risk factors include maternal education level, maternity activity, maternal civil status, mother age, maternal and paternal nationality of origin and child gender don't have an association with risk of low birth weight, all statistical analysis with a $p$-value $>0.05$.

The univariate analysis (table 4) of the Apgar at one minute considering that the event is depressed. Risk factors associated to the outcome statistically significant include: The Multiple birth is significantly associated with depressed new born for an OR $(95 \%$ C.I $)=2.37(1.24-4.5)$ P-value $\mathbf{0 . 0 1 5 7}$; The mode of delivery is statistically associated with depressed baby (low Apgar) especially for new born delivered with instrumental vaginal birth and caesarean respectively for an OR $(95 \%$ C.I) $=3.20(1.98-5.17)$ and OR $(95 \%$ C.I $)=2.39(1.61-3.56)$ for a global P-value $<0.001$. Assisted delivery are associated with depressed new born (low Apgar) for OR (05\% C.I) 2.74 (1.94-3.87), global P-value <0.001. Boys were exposed to lower Apgar compare to counterpart girl with OR (95\% C.I) 1.50 (1.07-2.11), global P-Value 0.0173. Preterm birth is statistically associated with low Apgar (depressed) at delivery OR (95\% C.I) 3.35(2.28-4.91), P-Value <0.001. As mentioned for its association with low birth weight it appears to be statistically with depressed babies. Some presentations of the baby were associated with depressed new born (low Apgar): other head presentation OR (95\% C.I) 2.79(1.12-6.97), seat presentation with OR (95\% C.I) 2.01(1.03-3.93). However other presentations are happened to be protective with OR (95\% C.I) 0.68(0.38-1.21), $p$-value 0.0401. Transverse presentation with OR (95\% C.I) 1.11(0.14-8.81) for a global $p$-value 0.0401 was not significant considering its confidence interval.

Table 4. Effect of medical intervention, child and parent's characteristics (health and socio-economics status) on Apgar score at one minute

\begin{tabular}{lllll}
\hline Parents Characteristics & $\begin{array}{l}\text { Depressed } \\
\mathbf{n = 1 5 3}\end{array}$ & $\begin{array}{l}\text { Normal } \\
\mathbf{n = 1 6 7 7}\end{array}$ & OR (CI 95\%) & p-value \\
\hline $\begin{array}{l}\text { Maternal activity } \\
\text { without occupation }\end{array}$ & 7.62 & 92.38 & 1 & 0.2989 \\
\hline Medical risk factor & 8.97 & 91.03 & $1.10(0.781-1.55)$ & \\
No & 7.75 & 92.25 & 1 & $0.0693^{*}$ \\
Yes & 12.4 & 87.6 & $1.68(1.09-2.58)$ & \\
Missing & 7.73 & 92.27 & $0.99(0.56-1.75)$ & \\
\hline Mother age & & & & \\
Young mother & 10.42 & 89.58 & $1.33(0.51-3.42)$ & $0.6387^{*}$ \\
Middle age mother & 8.03 & 91.97 & 1 & \\
Advanced age mother & 9.33 & 90.67 & $1.17(0.79-1.75)$ & \\
\hline Multiple birth & & & & \\
Yes & 17.14 & 82.86 & $2.37(1.24-4.5)$ & $\mathbf{0 . 0 1 5 7}$ \\
No & 8.01 & 91.99 & 1 & \\
\hline Delivery & & & & $<$ \\
Normal & 5.97 & 94.03 & 1 & \\
Instrumental vaginal birth & 16.88 & 83.12 & $3.20(1.98-5.17)$ & \\
Caesarean & 13.21 & 86.79 & $2.39(1.61-3.56)$ & \\
\hline Assistance & & & & $<$ \\
Yes & 14.52 & 85.48 & $2.74(1.94-3.87)$ & $<\mathbf{0 . 0 0 1}$ \\
No & 5.82 & 94.18 & 1 & \\
\hline Child gender & & & & \\
Boy & 9.8 & 90.2 & $1.50(1.07-2.11)$ & $\mathbf{0 . 0 1 7 3}$ \\
Girl & 6.74 & 93.26 & 1 & \\
\hline Gestational age & & & & \\
Normal & 6.63 & 93.37 & 1 & \\
\hline
\end{tabular}




\begin{tabular}{lllll} 
Preterm & 19.23 & 80.77 & $3.35(2.28-4.91)$ & \\
\hline Child Presentation & & & & \multirow{2}{*}{.0401* } \\
Head down & 8.2 & 91.8 & 1 & \\
Other head presentation & 20 & 80 & $2.79(1.12-6.97)$ & \\
seat & 15.28 & 84.72 & $2.01(1.03-3.93)$ & \\
Transverses & 9.09 & 90.91 & $1.11(0.14-8.81)$ & \\
Missing/other & 5.79 & 94.21 & $0.68(0.38-1.21)$ & \\
\hline
\end{tabular}

The multivariate analysis of birth weight for LBW providing the adjusted Odd ratio with risk factors in the explanatory modelling provide some critical information (table 5).

Women who delivered preterm, their newborn are strongly associated with low birth weight aOR (95\%C.I.) 17, 0 (10, 71-27, 06), P-value <0.001. Women with multiple birth were at risk delivering new born with LBW for OR (95\% C.I) 5.78 (3.05-10.97), P-Value <0.001. Women with medical risk factors were statistically associated with LBW for aOR (95\% C.I) 2.43 (1.47-4.02), P-value 0.0023. No association was found for single women and child gender neither girl nor boy in the model.

Table 5. The results of the logistic regression modelling for low birth weight with risk factors

\begin{tabular}{|c|c|c|c|}
\hline & $\begin{array}{l}\text { Cases }=125(n=1736) \\
\operatorname{aOR}(95 \% \text { C.I })\end{array}$ & $p$-value & \\
\hline \multicolumn{4}{|c|}{ Child Gender } \\
\hline Girl & 1 & & \\
\hline Boy & $1.45(0.93-2.26)$ & 0.1 & \\
\hline \multicolumn{4}{|c|}{ Maternal civil status } \\
\hline Married & 1 & & \\
\hline No married & $0.6(0.37-0.97)$ & 0.038 & \\
\hline \multicolumn{4}{|c|}{ Medical risk factors } \\
\hline No & 1 & & \\
\hline Yes & $2.43(1.47-4.02)$ & $<0.001$ & $0.0023 *$ \\
\hline Missing & $1.36(0.66-2.80)$ & 0.393 & \\
\hline \multicolumn{4}{|c|}{ Gestational age } \\
\hline Normal & 1 & & \\
\hline Preterm & $17.00(10.71-27.06)$ & $<0.001$ & \\
\hline \multicolumn{4}{|c|}{ Multiple Birth } \\
\hline No & 1 & & \\
\hline Yes & $5.78(3.05-10.97)$ & $<0.001$ & \\
\hline
\end{tabular}

*Global P-value for test

The multivariate analysis of Apgar at one minute for Depressed new born providing the adjusted Odd ratio with risk factors in the explanatory model provide some critical information (table 6). Gestational age remains statistically significant and preterm gestational age are associated with very low Apgar for aOR (95\% C.I) 3.26 (2.16-4.91). the C.I of risk factors child presentation, child gender and medical assistance indicating that the exposure may not be statistically associated with the occurrence of low Apgar (Depressed) despite the significant $P$-value for child gender and medical assistance which appear being non-significant as containing the reference 1 which is the reference OR. 
DOI: $10.21522 / \mathrm{TIJPH} .2013 .05 .04 . A r t 017$

ISSN: $2520-3134$

Table 6. The results of the logistic regression modelling for Depressed with risks factors

\begin{tabular}{llll}
\hline & aOR $($ IC 95\%) & p value & \\
\hline Child presentation & & & \\
Head down & 1 & & \\
Other head presentation & $2.22(0.86-5.72)$ & 0.098 & $0.0647^{*}$ \\
seat & $0.84(0.40-1.77)$ & 0.659 & \\
Transverses & $0.30(0.037-2.51)$ & 0.27 & \\
Missing/other & $0.47(0.24-0.94)$ & 0.035 & \\
\hline Gestational age & & & \\
Normal & 1 & & \\
Preterm & $3.26(2.16-4.91)$ & $<\mathbf{0 . 0 0 1}$ \\
\hline Child gender & & & \\
girl & 1 & & \\
boy & $0.65(0.45-0.93)$ & 0.021 & \\
\hline Assistance & & \\
No & 1 & $<0.001$ \\
Yes & $0.40(0.27-0.58)$ & \\
\hline
\end{tabular}

*Global P-value for test

The association between the two outcomes was measured considering the birth weight as the exposition and Apgar as the outcome (event). The table7. Shows the association of low birth weight and low Apgar (depressed) at OR (95\% C.I) 3.43 (2.14-5.50) $P$-Value <0.001 for which is statistically significant. Preterm babies are therefore considered to be significantly associated with low Apgar.

Table 7. Association of birth weight and apgar score at one minute

\begin{tabular}{|c|c|c|c|c|}
\hline \multirow[b]{2}{*}{ Child Caracteristics } & \multicolumn{4}{|l|}{ Number $(\%)$} \\
\hline & $\begin{array}{l}\text { Cases }(n=149) \\
\text { Depressed }\end{array}$ & $\begin{array}{l}\text { Control }(n=1658) \\
\text { Normal }\end{array}$ & $\begin{array}{l}\text { OR }(95 \% \\
\text { C.I. })\end{array}$ & P-value \\
\hline \multicolumn{5}{|l|}{ Birth weight } \\
\hline $\begin{array}{l}\text { Low birth weight } \\
\text { Normal weight }\end{array}$ & $\begin{array}{l}26(17.45 \%) \\
123(82.55 \%)\end{array}$ & $\begin{array}{l}96(5.95) \\
1562(94.21)\end{array}$ & $\begin{array}{l}3.43(2.15- \\
5.48) \\
1\end{array}$ & $<0.001$ \\
\hline
\end{tabular}

Stratified by gestational age, the statistical interaction of the gestational age the as shown in the table 8 modifies the OR strength, it has an effect modification at OR (95\%C. I) 2.43 (1.5-3.93) has modify the trend of the association. But still significant, there is no influence of gestation age on Apgar score when the new born has already low birth weight. 
Table. 8. Effect of low birth weight on apgar one minute stratified by gestational age

\begin{tabular}{|c|c|c|c|c|}
\hline & & \multicolumn{3}{|c|}{ APGAR } \\
\hline STRATA & & $\begin{array}{l}\text { Child } \\
\text { caracteristics }\end{array}$ & & $\begin{array}{l}\text { OR } \\
(95 \% \\
\text { C.I. }) \\
\end{array}$ \\
\hline \multirow[t]{4}{*}{ Gestational Age } & Preterm & Low birth weight & & $\begin{array}{l}2.3(1.2- \\
4.5)\end{array}$ \\
\hline & & Normal weight & & \\
\hline & Normal Weight & $\begin{array}{l}\text { Low birth } \\
\text { weight }\end{array}$ & & $1.5(0.4-4.3)$ \\
\hline & & Normal weight & & \\
\hline \multirow{2}{*}{\multicolumn{2}{|c|}{$\begin{array}{l}\text { Crude } \\
\text { M-H combined }\end{array}$}} & & & $\begin{array}{l}3.4(2.2- \\
5.5)\end{array}$ \\
\hline & & & & $2.03(1.1-3.6)$ \\
\hline \multicolumn{2}{|c|}{ Test of homogeneity (M-H) } & $\operatorname{chi} 2(1)=0.551$ & $\begin{array}{l}\operatorname{Pr}>\text { chi } 2= \\
0.4580\end{array}$ & \\
\hline \multicolumn{5}{|c|}{$\begin{array}{l}\text { Gestational age is a confounding on the effect of birth weight on Apgar Score at } 1 \\
\text { minute } \\
\text { cutt off: } 20 \%(\mathrm{Orw}=40 \%)\end{array}$} \\
\hline
\end{tabular}

The effect of low birth weight on Apgar at one minute stratified by medical assistance (table not presented here) has no effect modification of the OR (95\%) 3.43(2.15-5.48) $\mathrm{p}$ value $0<.0 .001$

\section{Discussion}

In this cohort study, main risks factors related to low birth weight include medical risk factors, multiple birth and gestational age. After the multiple regression, it appears that medical risk factors, multiple birth and gestational age are strongly associated with risk of low birth weight for the cutoff of LBW $<2500$ grams. This has been as well documented in other studies $(1,2)$ but researchers would like consider measure taken at delivery for very small new born for their gestational age. Gestational age need to be considered with attention, preterm birth being significantly associated with low birth weight in univariate and multivariate analysis respectively OR (95\%C.I.) 27.14 (17.75-41.51) p-value< 0.001 and 17,00 (10, $71-27,06) \mathrm{p}$-value $<0.001$. Even birth weight stratified by gestational age has an effect modification and may require thus to improve maternal condition (pregnant women with related medical risk factors). Other factors were found not associated with low birth weight as presented in univariate and multiple regression analysis which include parent's socio-demographic factors maternal activity, maternal education level, maternal civil status, mother age, nationality of origin of both parents and new born sex gender between girl and boys.

However, Md Monirujjaman et al. provided information on the existence of difference in birth weight considering these socio-economic factors. Again, these factors should not be considered in isolation as linked to other factors which include maternal food intake, medical factors and others potential life condition which may improve fetal condition.

The Apgar score at one minute in univariate some of the risk factors include multiple birth, mode of delivery, medical assistance child gender, gestational age and child presentation. The multiple regression presented different view of the odd to low Agar considering significantly the gestational age preterm, OR (95\%) 17(10.71-27.0) p value<0.001. Preterm appear to be a risk in both outcome (Birth weight and Apgar). Maternal medical risk factors also are associated with low Apgar. 
DOI: $10.21522 / \mathrm{TIJPH} .2013 .05 .04 . A r t 017$

ISSN: $2520-3134$

Studies has been conducted on the neonatal outcome considering Apgar at one and $5 \mathrm{~min}$. Sebastian Straube, Gerhard Jorch et al. and documented in their study no convincing associations between 5-min Apgar score and a variety of socio-economic factors of the mothers including country of origin, occupation, and smoking. The influence of socio-economic factors on Apgar scores seem to depend on the population studied and on precisely what socio-economic parameter is investigated. For example, a study from Spain found that perinatal complications, including an Apgar score of six or below, were not more frequent in the newborns of immigrant mothers compared to Spanish mothers.

Simon Graham, Lisa R Jackson Pulver et al. Conducted a study in Australian, reported that only 76.7\% of babies born to indigenous Australian mothers fell into a "healthy baby" category, as characterized by being a live birth, a singleton, born after 37-41 completed weeks' gestation, having a birthweight of 2,500-4,499 g, and a 5-min Apgar score of at least 7. For non-indigenous mothers, the rate of "healthy babies" was $85.0 \%$.

Johnson EB, Reed SD et al. founded in their study from Washington State comparing newborns of Somali immigrant women with those of black and white US-born women. Neonates born to Somali women were at increased risk of lower 5-min Apgar scores.

In the study Apgar score was not associated to any socio-demographic factor. However, some of the intervention were found to be protective in improving the new born outcome (good Apgar score at one minute, medical assistance in multiple logistic regression OR (95\% C.I.) 0.40(0.27-0.58) p-value <0.001 which suggest that medical assistance is needed and may improve the life new born. Other factors were not find associated with depressed (low Apgar) among new born.

The association of low birth weight and Apgar score is significantly associated OR (95\% C.I) 3.43 (2.15-5.48). Even when adjusted with potential modifiers, the medical assistance and gestational age for preterm with OR (95\% C.I) respectively of 3.1(1.89-5.01) p-value $0<.001$ and 2.43 (1.5-3.95) p-value 0.003 .

Strength of the study include availability of enough sample in the data base to enable study of the outcome under this study. Limitation of this cohort study include the information provided by women may not be reliable some of the information related to Apgar could collected from the hospital register to ensure reliability of information, the unavailability of data from walonia Brussel could increase the sample size and the strength as well.

Studies on hearing screening conducted by Bénédicte, Christelle S., Raphaël L. mention several medical risk factors as linked to neurological defect mainly the hearing loss which include medical risks factors (infections, LBW, Apgar>7)

\section{Conclusion}

In this cohort study, we noticed the influence of low birth weight on Apgar score.

Some risk factors need special deep public health consideration, mainly the Medical risk factors and gestational age for preterm delivery. Low birth weight newborn is at high risk of low Apgar score. Medical assistance during delivery was protective for babies with LBW to be depressed (Public Health advantages). The effect of birth weight on Apgar at one minute stratified by medical risk factor and medical assistance have no effect modification or confounding. Gestational age is a confounding on the effect of birth weight on Apgar at 1 minute

The improvement some predictors will improve condition of the mother and the new born with positive delivery outcome (new born of more than 2500 grams and high Apgar score $\geq 7$ ).

Deep studies are needed for parent's socio-demographic factors to exclude any possible association that may not have been addressed under this study

\section{Funding}

The study was supported by students himself 


\section{References}

[1]. Altman M, Sandström A, Petersson G, Frisell T, Cnattingius S, Stephansson O. Prolonged second stage of labor is associated with low Apgar score. Eur J Epidemiol. Springer Netherlands; 2015;30 (11):1209-15.

[2]. Graham S, Pulver LRJ, Wang YA, Kelly PM, Laws PJ, Grayson N, et al. The urban-remote divide for Indigenous perinatal outcomes. Med J Aust. 2007; 186 (10):509-12.

[3]. Hemming K, Hutton JL, Glinianaia S V, Jarvis SN, Platt MJ. Differences between European birthweight standards: impact on classification of "small for gestational age". Dev Med Child Neurol. 2006; 48(11):906-12.

[4]. ISSN 2347-954X (Print) () Scholars Academic and Scientific Publisher (An International Publisher for Academic and Scientific Resources) Maternal Obstetric and Morbidity Factors in Re ... 2016; (May).

[5]. J Pharm et al. Maternal Socio-demographic factors and anthropometric characteristics related to infant birth weight. 2013; 29(13):788-97.

[6]. Lie KK, Grøholt E-K, Eskild A. Association of cerebral palsy with Apgar score in low and normal birthweight infants: population based cohort study. BMJ. 2010; 341(oct06_6):c4990.

[7]. Levine EM, Ghai V, Barton JJ, Strom CM. Mode of delivery and risk od respiratory diseases in newborns. Obstet Gynecol. 2001; 97(6):1025-6.

[8]. Malin G, Morris R, Ahmad S, Riley R, Khan K. PP.03 Does the Apgar Score Matter? Investigating the Relationship Between a Low Score and Adverse Outcomes from Birth to Childhood. Arch Dis Child - Fetal Neonatal Ed. 2013; 98(Suppl 1):A83-A83.

[9]. Michalczuk M, Urban B, Chrzanowska-Grenda B, Ozi?? b?? o-Kupczyk M, Bakunowiczazarczyk A. An influence of birth weight, gestational age, and apgar score on pattern visual evoked potentials in children with history of prematurity. Neural Plast. 2015; 2015.

[10]. Montgomery KS. Apgar Scores: Examining the Long-term Significance. J Perinat Educ an ASPO/Lamaze Publ. 2000; 9(3):5-9.

[11]. Mori R, Shiraishi J, Negishi H, Fujimura M. Predictive value of Apgar score in infants with very low birth weight. Acta Paediatr Int J Paediatr. 2008; 97(6):720-3.

[12]. Negrini R, Assef LC, F DSC, E AJ. Delivery modes and the neonatal outcomes of low birth-weight neonates in a Brazilian reference health center Neonatální výsledky u novorozenců nízké porodní hmotnosti v brazilském referenčním centru polikliniky. 2016; 366-71.

[13]. Paper C. Hristova I., Zlatkov G., Slancheva B., Vakrilova L., Dimitrova V. Mode of delivery, condition at birth and mortality rate of very low birth weight neonates. Mode of delivery, condi... 2016; (May).

[14]. Salustiano EMA, Campos JADB, Ibidi SM, Ruano R, Zugaib M. Low Apgar scores at 5 minutes in a low risk population: maternal and obstetrical factors and postnatal outcome. Rev Assoc Med Bras. 2012; 58(5):587-93.

[15]. Straube S, Voigt M, Jorch G, Hallier E, Briese V, Borchardt U. Investigation of the association of Apgar score with maternal socio-economic and biological factors: An analysis of German perinatal statistics. Arch Gynecol Obstet. 2010; 282(2):135-41.

[16]. The INTERGROWTH-21 st Project. WwwThelancetCom. 2014; 384:857-68.

[17]. Vos B, Senterre C, Lagasse R, Levêque A. Newborn hearing screening programme in Belgium: a consensus recommendation on risk factors. BMC Pediatr. BMC Pediatrics; 2015; 15(1):160.

[18]. Villar J, Cheikh Ismail L, Victora CG, Ohuma EO, Bertino E, Altman DG, et al. International standards for newborn weight, length, and head circumference by gestational age and sex: the Newborn Cross-Sectional Study of WHO recommendations on interventions to improve preterm birth outcomes. 2015;

[19]. Wilcox AJ. On the importance--and the unimportance--of birthweight. Int J Epidemiol. 2001; 30(6):1233-41. 